\title{
Teaching and learning mathematics through error analysis
}

Sheryl J. Rushton ${ }^{*}$

*Correspondence:

sherylrushton@weber.edu

Weber State University,

1351 Edvalson St. MC 1304,

Ogden, UT 84408, USA

\begin{abstract}
Background: For decades, mathematics education pedagogy has relied most heavily on teachers, demonstrating correctly worked example exercises as models for students to follow while practicing their own exercises. In more recent years, incorrect exercises have been introduced for the purpose of student-conducted error analysis. Combining the use of correctly worked exercises with error analysis has led researchers to posit increased mathematical understanding. Combining the use of correctly worked exercises with error analysis has led researchers to posit increased mathematical understanding.
\end{abstract}

Methods: A mixed method design was used to investigate the use of error analysis in a seventh-grade mathematics unit on equations and inequalities. Quantitative data were used to establish statistical significance of the effectiveness of using error analysis and qualitative methods were used to understand participants' experience with error analysis.

Results: The results determined that there was no significant difference in posttest scores. However, there was a significant difference in delayed posttest scores.

Conclusion: In general, the teacher and students found the use of error analysis to be beneficial in the learning process.

Keywords: Error analysis, Correct and erroneous examples, Mathematics teaching practices, Standards of mathematical practices

\section{Background}

For decades, mathematics education pedagogy has relied most heavily on teachers demonstrating correctly worked example exercises as models for students to follow while practicing their own exercises [3]. In more recent years, incorrect exercises have been introduced for the purpose of student-conducted error analysis [17]. Conducting error analysis aligns with the Standards of Mathematical Practice $[18,19]$ and the Mathematics Teaching Practices [18]. Researchers posit a result of increased mathematical understanding when these practices are used with a combination of correctly and erroneously worked exercises $[1,4,8,11,15,16,18,19,23]$.

\section{Review of literature}

Correctly worked examples consist of a problem statement with the steps taken to reach a solution along with the final result and are an effective method for the initial acquisitions of procedural skills and knowledge $[1,11,26]$. Cognitive load theory $[1,11,25]$ explains the challenge of stimulating the cognitive process without overloading the

(c) The Author(s) 2018. This article is distributed under the terms of the Creative Commons Attribution 4.0 International License (http://creativecommons.org/licenses/by/4.0/), which permits unrestricted use, distribution, and reproduction in any medium, provided you give appropriate credit to the original author(s) and the source, provide a link to the Creative Commons license, and indicate if changes were made. 
student with too much essential and extraneous information that will limit the working memory and leave a restricted capacity for learning. Correctly worked examples focus the student's attention on the correct solution procedure which helps to avoid the need to search their prior knowledge for solution methods. Correctly worked examples free the students from performance demands and allow them to concentrate on gaining new knowledge $[1,11,16]$.

Error analysis is an instructional strategy that holds promise of helping students to retain their learning [16]. Error analysis consists of being presented a problem statement with the steps taken to reach a solution in which one or more of the steps are incorrect, often called erroneous examples [17]. Students analyze and explain the errors and then complete the exercise correctly providing reasoning for their own solution. Error analysis leads students to enact two Standards of Mathematical Practice, namely, (a) make sense of problems and persevere in solving them and (b) attend to precision [19].

Another of the Standards of Mathematical Practice suggests that students learn to construct viable arguments and comment on the reasoning of others [19]. According to Große and Renkl [11], students who attempted to establish a rationale for the steps of the solution learned more than those who did not search for an explanation. Teachers can assist in this practice by facilitating meaningful mathematical discourse [18]. "Arguments do not have to be lengthy, they simply need to be clear, specific, and contain data or reasoning to back up the thinking" [20]. Those data and reasons could be in the form of charts, diagrams, tables, drawings, examples, or word explanations.

Researchers [7, 21] found the process of explaining and justifying solutions for both correct and erroneous examples to be more beneficial for achieving learning outcomes than explaining and justifying solutions to correctly worked examples only. They also found that explaining why an exercise is correct or incorrect fostered transfer and led to better learning outcomes than explaining correct solutions only. According to Silver et al. [22], students are able to form understanding by classifying procedures into categories of correct examples and erroneous examples. The students then test their initial categories against further correct and erroneous examples to finally generate a set of attributes that defines the concept. Exposing students to both correctly worked examples and error analysis is especially beneficial when a mathematical concept is often done incorrectly or is easily confused [11].

Große and Renkl [11] suggested in their study involving university students in Germany that since errors are inherent in human life, introducing errors in the learning process encourages students to reflect on what they know and then be able to create clearer and more complete explanations of the solutions. The presentation of "incorrect knowledge can induce cognitive conflicts which prompt the learner to build up a coherent knowledge structure" [11]. Presenting a cognitive conflict through erroneously worked exercises triggers learning episodes through reflection and explanations, which leads to deeper understanding [29]. Error analysis "can foster a deeper and more complete understanding of mathematical content, as well as of the nature of mathematics itself" [4].

Several studies have been conducted on the use of error analysis in mathematical units $[1,16,17]$. The study conducted for this article differed from these previous studies in mathematical content, number of teachers and students involved in the study, and 
their use of a computer or online component. The most impactful differences between the error analysis studies conducted in the past and this article's study are the length of time between the posttest and the delayed posttest and the use of qualitative data to add depth to the findings. The previous studies found students who conducted error analysis work did not perform significantly different on the posttest than students who received a more traditional approach to learning mathematics. However, the students who conducted error analysis outperformed the control group in each of the studies on delayed posttests that were given 1-2 weeks after the initial posttest.

Loibl and Rummel [15] discovered that high school students became aware of their knowledge gaps in a general manner by attempting an exercise and failing. Instruction comparing the erroneous work with correctly worked exercises filled the learning gaps. Gadgil et al. [9] conducted a study in which students who compared flawed work to expertly done work were more likely to repair their own errors than students who only explained the expertly done work. This discovery was further supported by other researchers $[8,14,24]$. Each of these researchers found students ranging from elementary mathematics to university undergraduate medical school who, when given correctly worked examples and erroneous examples, learned more than students who only examined correctly worked examples. This was especially true when the erroneous examples were similar to the kinds of errors that they had committed [14]. Stark et al. [24] added that it is important for students to receive sufficient scaffolding in correctly worked examples before and alongside of the erroneous examples.

\section{Purpose}

The purpose of this study was to explore whether seventh-grade mathematics students could learn better from the use of both correctly worked examples and error analysis than from the more traditional instructional approach of solving their exercises in which the students are instructed with only correctly worked examples. The study furthered previous research on the subject of learning from the use of both correctly worked examples and error analysis by also investigating the feedback from the teacher's and students' experiences with error analysis. The following questions were answered in this study:

1. What was the difference in mathematical achievement when error analysis was included in students' lessons and assignments versus a traditional approach of learning through correct examples only?

2. What kind of benefits or disadvantages did the students and teacher observe when error analysis was included in students' lessons and assignments versus a traditional approach of learning through correct examples only?

\section{Methods}

A mixed method design was used to investigate the use of error analysis in a seventhgrade mathematics unit on equations and inequalities. Quantitative data were used to establish statistical significance of the effectiveness of using error analysis and qualitative methods were used to understand participants' experience with error analysis [6, 27]. 


\section{Participants}

Two-seventh-grade mathematics classes at an International Baccalaureate (IB) school in a suburban charter school in Northern Utah made up the control and treatment groups using a convenience grouping. One class of 26 students was the control group and one class of 27 students was the treatment group.

The same teacher taught both the groups, so a comparison could be made from the teacher's point of view of how the students learned and participated in the two different groups. At the beginning of the study, the teacher was willing to give error analysis a try in her classroom; however, she was not enthusiastic about using this strategy. She could not visualize how error analysis could work on a daily basis. By the end of the study, the teacher became very enthusiastic about using error analysis in her seventh grade mathematics classes.

The total group of participants involved 29 males and 24 females. About $92 \%$ of the participants were Caucasian and the other $8 \%$ were of varying ethnicities. Seventeen percent of the student body was on free or reduced lunch. Approximately $10 \%$ of the students had individual education plans (IEP).

\section{Materials}

A pretest and posttest were created to contain questions that would test for mathematical understanding on equations and inequalities using Glencoe Math: Your Common Core Edition CCSS [5] as a resource. The pretest was reused as the delayed posttest. Homework assignments were created for both the control group and the treatment group from the Glencoe Math: Your Common Core Edition CCSS textbook. However, the researcher rewrote two to three of the homework exercises as erroneous examples for the treatment group to find the error and fix the exercise with justifications (see Figs. 1, 2). Students from both groups used an Assignment Time Log to track the amount of time which they spent on their homework assignments.

$6.2-$ p. 451

Replace the corresponding questions from your textbook assignment with the given problems that have errors in the work.

For each problem, find the error and correct it to find the right answer to the problem.

Explain the error and what you did to complete the problem correctly.

\#6) $\frac{54}{9}=\frac{-9 d}{9}$

$$
\text { \#8) } \begin{aligned}
\frac{r}{20} & =-2 \\
r & =\frac{-2}{20}=-10 \\
r & =-10
\end{aligned}
$$

\#12) A certain hurricane travels at 20.88 kilometers per hour. The distance from Cuba to Key West is 145 kilometers. Write and solve a multiplication equation to find about how long it would take the hurricane to travel from Cuba to Key West.

$$
\begin{aligned}
& T=\text { time } \\
& T=20.88 \text { (145) } \\
& T=3215.52 \quad \text { It would take the hurricane } 3215.52 \text { hours to travel to Key West. }
\end{aligned}
$$

Fig. 1 Example of the rewritten homework exercises as equation erroneous examples 
$6.7-$ p. 509

Replace the corresponding questions from your textbook assignment with the given problems that have errors in the work.

For each problem, find the error and correct it to find the right answer to the problem.

Explain the error and what you did to complete the problem correctly.

\#2)

$$
\begin{aligned}
\frac{-3 s}{-3} & \geq \frac{33}{-3} \\
s & \geq-11
\end{aligned}
$$

\#8)

$$
\begin{aligned}
& \frac{h}{9}>\frac{1}{4} \\
& \frac{h}{9} \cdot 9>\frac{1}{4} \cdot 9 \\
& h>\frac{1}{36}
\end{aligned}
$$

\#12) Solve and graph

$$
\begin{aligned}
& \frac{s}{-6}>-16 \\
& \frac{s}{-6} \cdot-6>-16 \cdot-6 \\
& s>96
\end{aligned}
$$

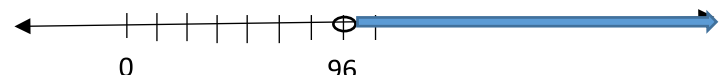

Fig. 2 Example of the rewritten homework exercises as inequality erroneous examples

\section{Procedure}

Both the control and the treatment groups were given the same pretest for an equations and inequality unit. The teacher taught both the control and treatment groups the information for the new concepts in the same manner. The majority of the instruction was done using the direct instruction strategy. The students in both groups were allowed to work collaboratively in pairs or small groups to complete the assignments after instruction had been given. During the time she allotted for answering questions from the previous assignment, she would only show the control group the exercises worked correctly. However, for the treatment group, the teacher would write errors which she found in the students' work on the board. She would then either pair up the students or create small groups and have the student discuss what errors they noticed and how they would fix them. Often, the teacher brought the class together as a whole to discuss what they discovered and how they could learn from it.

The treatment group was given a homework assignment with the same exercises as the control group, but including the erroneous examples. Students in both the control and treatment groups were given the Assignment Time Log to keep a record of how much time was spent completing each homework assignment.

At the end of each week, both groups took the same quiz. The quizzes for the control group received a grade, and the quiz was returned without any further attention. If a student asked how to do an exercise, the teacher only showed the correct example. The teacher graded the quizzes for the treatment group using the strategy found in the Teaching Channel's video "Highlighting Mistakes: A Grading Strategy" [2]. She marked the quizzes by highlighting the mistakes; no score was given. The students were allowed time in class or at home to make corrections with justifications.

The same posttest was administered to both groups at the conclusion of the equation and inequality chapter, and a delayed posttest was administered 6 weeks later. 
The delayed posttest also asked the students in the treatment group to respond to an open-ended request to "Please provide some feedback on your experience". The test scores were analyzed for significant differences using independent samples $t$ tests. The responses to the open-ended request were coded and analyzed for similarities and differences, and then, used to determine the students' perceptions of the benefits or disadvantages of using error analysis in their learning.

At the conclusion of gathering data from the assessments, the researcher interviewed the teacher to determine the differences which the teacher observed in the preparation of the lessons and students' participation in the lessons [6]. The interview with the teacher contained a variety of open-ended questions. These are the questions asked during the interview: (a) what is your opinion of using error analysis in your classroom at the conclusion of the study versus before the study began? (b) describe a typical classroom discussion in both the control group class and the treatment group class, (c) talk about the amount of time you spent grading, preparing, and teaching both groups, and (d) describe the benefits or disadvantages of using error analysis on a daily basis compared to not using error analysis in the classroom. The responses from the teacher were entered into a computer, coded, and analyzed for thematic content $[6,27]$. The themes that emerged from coding the teacher's responses were used to determine the kind of benefits or disadvantages observed when error analysis was included in students' lessons and assignments versus a traditional approach of learning through correct examples only from the teacher's point of view.

\section{Findings and discussion}

\section{Mathematical achievement}

Preliminary analyses were carried out to evaluate assumptions for the $t$ test. Those assumptions include: (a) the independence, (b) normality tested using the Shapiro-Wilk test, and (c) homogeneity of variance tested using the Levene Statistic. All assumptions were met.

The Levene Statistic for the pretest scores $(p>0.05)$ indicated that there was not a significant difference in the groups. Independent samples $t$ tests were conducted to determine the effect error analysis had on student achievement determined by the difference in the means of the pretest and posttest and of the pretest and delayed posttest. There was no significant difference in the scores from the posttest for the control group $(M=8.23, \mathrm{SD}=5.67)$ and the treatment group $(M=9.56, \mathrm{SD}=5.24) ; t(51)=0.88$, $p=0.381$. However, there was a significant difference in the scores from the delayed posttest for the control group $(M=5.96, \mathrm{SD}=4.90)$ and the treatment group $(M=9.41$, $\mathrm{SD}=4.77) ; t(51)=2.60, p=0.012$. These results suggest that students can initially learn mathematical concepts through a variety of methods. Nevertheless, the retention of the mathematical knowledge is significantly increased when error analysis is added to the students' lessons, assignments, and quizzes. It is interesting to note that the difference between the means from the pretest to the posttest was higher in the treatment group $(M=9.56)$ versus the control group $(M=8.23)$, implying that even though there was not a significant difference in the means, the treatment group did show a greater improvement. 
The Assignment Time Log was completed by only $19 \%$ of the students in the treatment group and $38 \%$ of the students in the control group. By having such a small percentage of each group participate in tracking the time spent completing homework assignment, the results from the $t$ test analysis cannot be used in any generalization. However, the results from the analysis were interesting. The mean time spent doing the assignments for each group was calculated and analyzed using an independent samples $t$ test. There was no significant difference in the amount of time students which spent on their homework for the control group $(M=168.30, \mathrm{SD}=77.41)$ and the treatment group $(M=165.80$, $\mathrm{SD}=26.53) ; t(13)=0.07, p=0.946$. These results suggest that the amount of time that students spent on their homework was close to the same whether they had to do error analyses (find the errors, fix them, and justify the steps taken) or solve each exercise in a traditional manner of following correctly worked examples. Although the students did not spend a significantly different amount of time outside of class doing homework, the treatment group did spend more time during class working on quiz corrections and discussing error which could attribute to the retention of knowledge.

\section{Feedback from participants}

All students participating in the current study submitted a signed informed consent form. Students process mathematical procedures better when they are aware of their own errors and knowledge gaps [15]. The theoretical model of using errors that students make themselves and errors that are likely due to the typical knowledge gaps can also be found in works by other researchers such as Kawasaki [14] and VanLehn [29]. Highlighting errors in the students' own work and in typical errors made by others allowed the participants in the treatment group the opportunity to experience this theoretical model. From their experiences, the participants were able to give feedback to help the researcher delve deeper into what the thoughts were of the use of error analysis in their mathematics classes than any other study provided $[1,4,7-9,11,14-17,21,23-26$, 29]. Overall, the teacher and students found the use of error analysis in the equations and inequalities unit to be beneficial. The teacher pointed out that the discussions in class were deeper in the treatment group's class. When she tried to facilitate meaningful mathematical discourse [18] in the control group class, the students were unable to get to the same level of critical thinking as the treatment group discussions. In the openended question at the conclusion of the delayed posttest ("Please provide some feedback on your experience."), the majority (86\%) of the participants from the treatment group indicated that the use of erroneous examples integrated into their lessons was beneficial in helping them recognize their own mistakes and understanding how to correct those mistakes. One student reported, "I realized I was doing the same mistakes and now knew how to fix it". Several (67\%) of the students indicated learning through error analysis made the learning process easier for them. A student commented that "When I figure out the mistake then I understand the concept better, and how to do it, and how not to do it".

When students find and correct the errors in exercises, while justifying themselves, they are being encouraged to learn to construct viable arguments and critique the reasoning of others [19]. This study found that explaining why an exercise is correct or incorrect fostered transfer and led to better learning outcomes than explaining correct 
solutions only. However, some of the higher level students struggled with the explanation component. According to the teacher, many of these higher level students who typically do very well on the homework and quizzes scored lower on the unit quizzes and tests than the students expected due to the requirement of explaining the work. In the past, these students had not been justifying their thinking and always got correct answers. Therefore, providing reasons for erroneous examples and justifying their own process were difficult for them.

Often teachers are resistant to the idea of using error analysis in their classroom. Some feel creating erroneous examples and highlighting errors for students to analyze is too time-consuming [28]. The teacher in this study taught both the control and treatment groups, which allowed her the perspective to compare both methods. She stated, "Grading took about the same amount of time whether I gave a score or just highlighted the mistakes". She noticed that having the students work on their errors from the quizzes and having them find the errors in the assignments and on the board during class time ultimately meant less work for her and more work for the students.

Another reason behind the reluctance to use error analysis is the fact that teachers are uncertain about exposing errors to their students. They are fearful that the discussion of errors could lead their students to make those same errors and obtain incorrect solutions [28]. Yet, most of the students' feedback stated the discussions in class and the error analyses on the assignments and quizzes helped them in working homework exercises correctly. Specifically, they said figuring out what went wrong in the exercise helped them solve that and other exercises. One student said that error analysis helped them "do better in math on the test, and I actually enjoyed it". Nevertheless, 2 of the 27 participating students in the treatment group had negative comments about learning through error analysis. One student did not feel that correcting mistakes showed them anything, and it did not reinforce the lesson. The other student stated being exposed to error analysis did, indeed, confuse them. The student kept thinking the erroneous example was a correct answer and was unsure about what they were supposed to do to solve the exercise.

When the researcher asked the teacher if there were any benefits or disadvantages to using error analysis in teaching the equations and inequalities unit, she said that she thoroughly enjoyed teaching using the error analysis method and was planning to implement it in all of her classes in the future. In fact, she found that her "hands were tied" while grading the control group quizzes and facilitating the lessons. She said, "I wanted to have the students find their errors and fix them, so we could have a discussion about what they were doing wrong". The students also found error analysis to have more benefits than disadvantages. Other than one student whose response was eliminated for not being on topic and the two students with negative comments, the other 24 of the students in the treatment group had positive comments about their experience with error analysis. When students had the opportunity to analyze errors in worked exercises (error analysis) through the assignments and quizzes, they were able to get a deeper understanding of the content and, therefore, retained the information longer than those who only learned through correct examples.

Discussions generated in the treatment group's classroom afforded the students the opportunity to critically reason through the work of others and to develop possible 
arguments on what had been done in the erroneous exercise and what approaches might be taken to successfully find a solution to the exercise. It may seem surprising that an error as simple as adding a number when it should have been subtracted could prompt a variety of questions and lead to the students suggesting possible ways to solve and check to see if the solution makes sense. In an erroneous exercise presented to the treatment group, the students were provided with the information that two of the three angles of a triangle were $35^{\circ}$ and $45^{\circ}$. The task was to write and solve an equation to find the missing measure. The erroneous exercise solver had created the equation: $x+35+45=180$. Next was written $x+80=180$. The solution was $x=260^{\circ}$. In the discussion, the class had on this exercise, the conclusion was made that the error occurred when 80 was added to 180 to get a sum of 260 . However, the discussion progressed finding different equations and steps that could have been taken to discover the missing angle measure to be $100^{\circ}$ and why $260^{\circ}$ was an unreasonable solution. Another approach discussed by the students was to recognize that to say the missing angle measure was $260^{\circ}$ contradicted with the fact that one angle could not be larger than the sum of the angle measures of a triangle. Analyzing the erroneous exercises gave the students the opportunity of engaging in the activity of "explaining" and "fixing" the errors of the presented exercise as well as their own errors, an activity that fostered the students' learning.

\section{Conclusion}

The students participating in both the control and treatment groups from the twoseventh-grade mathematics classes at the IB school in a suburban charter school in Northern Utah initially learned the concepts taught in the equations and inequality unit statistically just as well with both methods of teaching. The control group had the information taught to them with the use of only correctly worked examples. If they had a question about an exercise which they did wrong, the teacher would show them how to do the exercise correctly and have a discussion on the steps required to obtain the correct solutions. On their assignments and quizzes, the control group was expected to complete the work by correctly solving the equations and inequalities in the exercise, get a score on their work, and move on to the next concept. On the other hand, the students participating in the treatment group were given erroneous examples within their assignments and asked to find the errors, explain what had been done wrong, and then correctly solve the exercise with justifications for the steps they chose to use. During lessons, the teacher put erroneous examples from the students' work on the board and generated paired, small groups, or whole group discussion of what was wrong with the exercise and the different ways to do it correctly. On the quizzes, the teacher highlighted the errors and allowed the students to explain the errors and justify the correct solution.

Both the method of teaching using error analysis and the traditional method of presenting the exercise and having the students solve it proved to be just as successful on the immediate unit summative posttest. However, the delayed posttest given 6 weeks after the posttest showed that the retention of knowledge was significantly higher for the treatment group. It is important to note that the fact that the students in the treatment group were given more time to discuss the exercises in small groups and as a whole class could have influenced the retention of mathematical knowledge just as much or more than the treatment of using error analysis. Researchers have proven academic 
advantages of group work for students, in large part due to the perception of students having a secure support system, which cannot be obtained when working individually $[10,12,13]$.

The findings of this study supported the statistical findings of other researchers $[1,16$, 17], suggesting that error analysis may aid in providing a richer learning experience that leads to a deeper understanding of equations and inequalities for long-term knowledge. The findings of this study also investigated the teacher's and students' perceptions of using error analysis in their teaching and learning. The students and teacher used for this study were chosen to have the same teacher for both the control and treatment groups. Using the same teacher for both groups, the researcher was able to determine the teacher's attitude toward the use of error analysis compared to the non-use of error analysis in her instruction. The teacher's comments during the interview implied that she no longer had an unenthusiastic and skeptical attitude toward the use of error analysis on a daily basis in her classroom. She was "excited to implement the error analysis strategy into the rest of her classes for the rest of the school year". She observed error analysis to be an effective way to deal with common misconceptions and offer opportunities for students to reflect on their learning from their errors. The process of error analysis assisted the teacher in supporting productive struggle in learning mathematics [18] and created opportunity for students to have deep discussions about alternative ways to solve exercises. Error analysis also aided in students' discovery of their own errors and gave them possible ways to correct those errors. Learning through the use of error analysis was enjoyable for many of the participating students.

According to the NCTM [18], effective teaching of mathematics happens when a teacher implements exercises that will engage students in solving and discussing tasks that promote mathematical reasoning and problem solving. Providing erroneous examples allowed discussion, multiple entry points, and varied solution strategies. Both the teacher and the students participating in the treatment group came to the conclusion that error analysis is a beneficial strategy to use in the teaching and learning of mathematics. Regardless of the two negative student comments about error analysis not being helpful for them, this researcher recommends the use of error analysis in teaching and learning mathematics.

The implications of the treatment of teaching students mathematics through the use of error analysis are that students' learning could be fostered and retention of content knowledge may be longer. When a teacher is able to have their students' practice critiquing the reasoning of others and creating viable arguments [19] by analyzing errors in mathematics, the students not only are able to meet the Standard of Mathematical Practice, but are also creating a lifelong skill of analyzing the effectiveness of "plausible arguments, distinguish correct logic or reasoning from that which is flawed, and-if there is a flaw in an argument-explain what it is" ([19], p. 7).

\section{Limitations and future research}

This study had limitations. The sample size was small to use the same teacher for both groups. Another limitation was the length of the study only encompassed one unit. Using error analysis could have been a novelty and engaged the students more than it would when the novelty wore off. Still another limitation was the study that was 
conducted at an International Baccalaureate (IB) school in a suburban charter school in Northern Utah, which may limit the generalization of the findings and implications to other schools with different demographics.

This study did not have a separation of conceptual and procedural questions on the assessments. For a future study, the creation of an assessment that would be able to determine if error analysis was more helpful in teaching conceptual mathematics or procedural mathematics could be beneficial to teachers as they plan their lessons. Another suggestion for future research would be to gather more data using several teachers teaching both the treatment group and the control group.

\section{Additional file}

Additional file 1: Error analysis data.

\section{Acknowledgements}

Not applicable.

Competing interests

The author declares that no competing interests.

Availability of data and materials

A spreadsheet of the data will be provided as an Additional file 1: Error analysis data.

Consent for publication

Not applicable.

Ethics approval and consent to participate

All students participating in the current study submitted a signed informed consent form.

\section{Funding}

Not applicable.

\section{Publisher's Note}

Springer Nature remains neutral with regard to jurisdictional claims in published maps and institutional affiliations.

Received: 7 March 2017 Accepted: 16 January 2018

Published online: 30 January 2018

\section{References}

1. Adams, D.M., McLaren, B.M., Durkin, K., Mayer, R.E., Rittle-Johnson, B., Isotani, S., van Velsen, M.: Using erroneous examples to improve mathematics learning with a web-based tutoring system. Comput. Hum. Behav. 36, 401-411 (2014)

2. Alcala, L.: Highlighting mistakes: a grading strategy. The teaching channel. https://www.teachingchannel.org/ videos/math-test-grading-tips

3. Atkinson, R.K., Derry, S.J., Renkl, A., Wortham, D.: Learning from examples: instructional Principles from the worked examples research. Rev. Educ. Res. 70(2), 181-214 (2000)

4. Borasi, R.: Exploring mathematics through the analysis of errors. Learn. Math. 7(3), 2-8 (1987)

5. Carter, J.A., Cuevas, G.J., Day, R., Malloy, C., Kersaint, G., Luchin, B.M., Willard, T.: Glencoe math: your common core edition CCSS. Glencoe/McGraw-Hill, Columbus (2013)

6. Creswell, J.: Research design: qualitative, quantitative, and mixed methods approaches, 4th edn. Sage Publications, Thousand Oaks (2014)

7. Curry, L. A.: The effects of self-explanations of correct and incorrect solutions on algebra problem-solving performance. In: Proceedings of the 26th annual conference of the cognitive science society, vol. 1548. Erlbaum, Mahwah (2004)

8. Durkin, K., Rittle-Johnson, B.: The effectiveness of using incorrect examples to support learning about decimal magnitude. Learn. Instr. 22(3), 206-214 (2012)

9. Gadgil, S., Nokes-Malach, T.J., Chi, M.T.: Effectiveness of holistic mental model confrontation in driving conceptual change. Learn. Instr. 22(1), 47-61 (2012)

10. Gaudet, A.D., Ramer, L.M., Nakonechny, J., Cragg, J.J., Ramer, M.S.: Small-group learning in an upper-level university biology class enhances academic performance and student attitutdes toward group work. Public Libr. Sci. One $\mathbf{5}$, $1-9(2010)$ 
11. Große, C.S., Renkl, A.: Finding and fixing errors in worked examples: can this foster learning outcomes? Learn. Instr. 17(6), 612-634 (2007)

12. Janssen, J., Kirschner, F., Erkens, G., Kirschner, P.A., Paas, F.: Making the black box of collaborative learning transparent: combining process-oriented and cognitive load approaches. Educ. Psychol. Rev. 22, 139-154 (2010)

13. Johnson, D.W., Johnson, R.T.: An educational psychology success story: social interdependence theory and cooperative learning. Educ. Res. 38, 365-379 (2009)

14. Kawasaki, M.: Learning to solve mathematics problems: the impact of incorrect solutions in fifth grade peers' presentations. Jpn. J. Dev. Psychol. 21 (1), 12-22 (2010)

15. Loibl, K., Rummel, N.: Knowing what you don't know makes failure productive. Learn. Instr. 34, 74-85 (2014)

16. McLaren, B.M., Adams, D., Durkin, K., Goguadze, G., Mayer, R.E., Rittle-Johnson, B., Van Velsen, M.: To err is human, to explain and correct is divine: a study of interactive erroneous examples with middle school math students. 21st Century learning for 21st Century skills, pp. 222-235. Springer, Berlin (2012)

17. McLaren, B.M., Adams, D.M., Mayer, R.E.: Delayed learning effects with erroneous examples: a study of learning decimals with a web-based tutor. Int. J. Artif. Intell. Educ. 25(4), 520-542 (2015)

18. National Council of Teachers of Mathematics (NCTM): Principles to actions: ensuring mathematical success for all. Author, Reston (2014)

19. National Governors Association Center for Best Practices \& Council of Chief State School Officers (NGA Center and CCSSO): Common core state standards. Authors, Washington, DC (2010)

20. O'Connell, S., SanGiovanni, J.: Putting the practices into action: Implementing the common core standards for mathematical practice K-8. Heinemann, Portsmouth (2013)

21. Siegler, R.S.: Microgenetic studies of self-explanation. Microdevelopment: transition processes in development and learning, pp. 31-58. Cambridge University Press, New York (2002)

22. Silver, H.F., Strong, R.W., Perini, M.J.: The strategic teacher: Selecting the right research-based strategy for every lesson. ASCD, Alexandria (2009)

23. Sisman, G.T., Aksu, M.: A study on sixth grade students' misconceptions and errors in spatial measurement: length, area, and volume. Int. J. Sci. Math. Educ. 14(7), 1293-1319 (2015)

24. Stark, R., Kopp, V., Fischer, M.R.: Case-based learning with worked examples in complex domains: two experimental studies in undergraduate medical education. Learn. Instr. 21 (1), 22-33 (2011)

25. Sweller, J.: Cognitive load during problem solving: effects on learning. Cognitive Sci. 12, 257-285 (1988)

26. Sweller, J., Cooper, G.A.: The use of worked examples as a substitute for problem solving in learning algebra. Cognit. Instr. 2(1), 59-89 (1985)

27. Tashakkori, A., Teddlie, C.: Sage handbook of mixed methods in social \& behavioral research, 2nd edn. Sage Publications, Thousand Oaks (2010)

28. Tsovaltzi, D., Melis, E., McLaren, B.M., Meyer, A.K., Dietrich, M., Goguadze, G.: Learning from erroneous examples: when and how do students benefit from them? Sustaining TEL: from innovation to learning and practice, pp. 357-373. Springer, Berlin (2010)

29. VanLehn, K.: Rule-learning events in the acquisition of a complex skill: an evaluation of CASCADE. J. Learn. Sci. 8(1), 71-125 (1999)

\section{Submit your manuscript to a SpringerOpen ${ }^{\odot}$ journal and benefit from:}

Convenient online submission

Rigorous peer review

- Open access: articles freely available online

- High visibility within the field

Retaining the copyright to your article

Submit your next manuscript at $\gg$ springeropen.com 